\title{
Regulation and Identity of Florigen: FLOWERING LOCUS T Moves Center Stage
}

\section{Franziska Turck, Fabio Fornara, and George Coupland}

\author{
Max Planck Institute for Plant Breeding, D 50829 Cologne, Germany; \\ email: coupland@mpiz-koeln.mpg.de
}

Annu. Rev. Plant Biol. 2008. 59:573-94

The Annual Review of Plant Biology is online at plant.annualreviews.org

This article's doi:

10.1146/annurev.arplant.59.032607.092755

Copyright (C) 2008 by Annual Reviews.

All rights reserved

$1543-5008 / 08 / 0602-0573 \$ 20.00$

\section{Key Words}

photoperiod, systemic signaling, floral transition, light-dependent protein stability, CONSTANS

\begin{abstract}
The transition from vegetative to reproductive growth is controlled by day length in many plant species. Day length is perceived in leaves and induces a systemic signal, called florigen, that moves through the phloem to the shoot apex. At the shoot apical meristem (SAM), florigen causes changes in gene expression that reprogram the SAM to form flowers instead of leaves. Analysis of flowering of Arabidopsis thaliana placed the CONSTANS/FLOWERING LOCUS T (CO/FT) module at the core of a pathway that promotes flowering in response to changes in day length. We describe progress in defining the molecular mechanisms that activate this module in response to changing day length and the increasing evidence that FT protein is a major component of florigen. Finally, we discuss conservation of FT function in other species and how variation in its regulation could generate different flowering behaviors.
\end{abstract}




\section{Contents}

INTRODUCTION............... 574

INDUCTION OF FLOWERING

BY PHOTOPERIOD IN

ARABIDOPSIS AND

THE EXTERNAL

COINCIDENCE MODEL ..... 574

ACTIVATION OF $F T$

TRANSCRIPTION BY CO..... 578

CLASSICAL STUDIES

DEMONSTRATED THE

INVOLVEMENT OF

SYSTEMIC SIGNALING IN

PHOTOPERIODIC

FLOWERING .............. 579

ANALYSIS OF THE SPATIAL

REGULATION OF THE

PHOTOPERIODIC PATHWAY

LINKS FT PROTEIN AND

FLORIGEN .................. 579

THE ROLE OF FT IN THE

SHOOT APICAL MERISTEM .. 583

$F T$-RELATED GENES

IN ARABIDOPSIS ............ 584

FLOWERING OF ARABIDOPSIS

UNDER SHORT DAYS ........ 585

CONSERVATION OF THE

CO/FT MODULE AND ITS

REGULATION IN

OTHER SPECIES ............ 586

PERSPECTIVES ............... 588

\section{INTRODUCTION}

The life cycles of many plants are synchronized to the changing seasons. This response is particularly important at high latitudes, where extreme changes in environmental conditions occur at different times of the year. Perception of changes in day length is one of the major ways in which plants detect the changing seasons. Garner \& Allard $(24,25)$, who were the first to describe this process in detail, referred to it as photoperiodism. These observations captured the imagination of plant researchers and attempts to explain the underlying mechanisms led to the discovery of fundamental plant processes such as the existence of phytochrome as a photoreceptor, systemic signaling from the leaf to the shoot apex during the initiation of flower development, and the role of circadian rhythms as the timekeeping mechanism. Many influential reviews dealing with these issues have appeared in various Annual Reviews series during the past 50 years, and each generation of researchers has approached the same biological problem with the tools available to them $(8,22,46,48,83,93,102)$. This review describes the recent progress made mainly in Arabidopsis using the tools of molecular genetics, and it summarizes our current answers to the questions posed by the observations of Garner \& Allard (24, 25).

\section{INDUCTION OF FLOWERING BY PHOTOPERIOD IN ARABIDOPSIS AND THE EXTERNAL COINCIDENCE MODEL}

Genetic approaches applied in Arabidopsis thaliana provided insight into the molecular mechanisms controlling photoperiodic responses. Recent reviews have described in detail the results of these approaches $(4,6$, $32,34,38,67,79)$. Arabidopsis is a facultative long-day plant that flowers earlier under long days (LDs) of $16 \mathrm{~h}$ of light than under short days (SDs) of 8 or $10 \mathrm{~h}$ of light. The photoperiodic pathway mutants co (constans), gi (gigantea), cry2 (cryptochrome), flowering locus $d(f d)$, flowering locus $t(f t)$, fe, and fwa flowered later than wild-type plants under LDs but at the same time as wild-type plants under SDs. The sequences of all these genes have now been published, with the exception of $F E(1,23,27,40,44,70,84,95)$, and they were proposed to comprise a single regulatory pathway, called the photoperiodic or long-day pathway, that promotes flowering specifically in response to LDs. 
The GI-CO-FT proteins act in this order at the core of the photoperiodic pathway, and their regulation results in $F T$ transcription under LDs but not SDs (Figures 1 and 2). $C O$ mRNA is present under both LDs and SDs and is regulated by the circadian clock, so that it rises in abundance between $10 \mathrm{~h}$ and $12 \mathrm{~h}$ after dawn. GI increases $C O$ mRNA abundance $(62,78,85)$. Under SDs $C O$ mRNA accumulates only during the night, whereas under LDs substantial expression is detected toward the end of the day. Furthermore, CO-mediated activation of FT transcription occurs at the end of the day under LDs but not under SDs (85). These comparisons

Figure 1

Circadian expression of key components in the photoperiod pathway. (a) GI and CDF1 are circadian clock-controlled positive and negative transcriptional regulators of $C O$, respectively. CDF1 directly binds to AAAG-elements within the $C O$ promoter. FKF1 is required for $\mathrm{CDF} 1$ degradation toward the middle of the day, thus permitting $C O$ mRNA levels to rise. (b) $C O$ mRNA expression differs between LDs and SDs such that a biphasic curve is observed only in LDs. (c) Accumulation of CO protein is strongly dependent on the coincidence of light and mRNA expression. CO protein is degraded by a proteasome-dependent mechanism, but it is stabilized toward the end of LDs through the concerted action of CRY2, CRY1, and PhyA. During the night, CO degradation is dependent on the presence of SPA1, SPA3, and SPA4. In the early morning, PhyB negatively regulates $\mathrm{CO}$ stability, which counteracts an early peak in CO that could be caused by high $C O$ mRNA levels at the end of the night. (d) FT mRNA production is a direct result of $\mathrm{CO}$ protein accumulation toward the end of LDs. White area: duration of light during LDs and SDs. Yellow area: light in LDs but dark in SDs. Blue area: dark in LDs and SDs.

Time in hours from dawn is represented below each diagram. ZT, zeitgeber time; SD, short day; LD, long day; SPA1, SUPRESSOR OF PHYA-105-1; GI, GIGANTEA; CDF1, CYCLING DOF FACTOR 1; CO, CONSTANS; FKF1, FLAVIN-BINDING FACTOR 1, KELCH REPEAT, F-BOX PROTEIN; CRY, CRYPTOCHROME; Phy, PHYTOCHROME; FT, FLOWERING LOCUS T. a

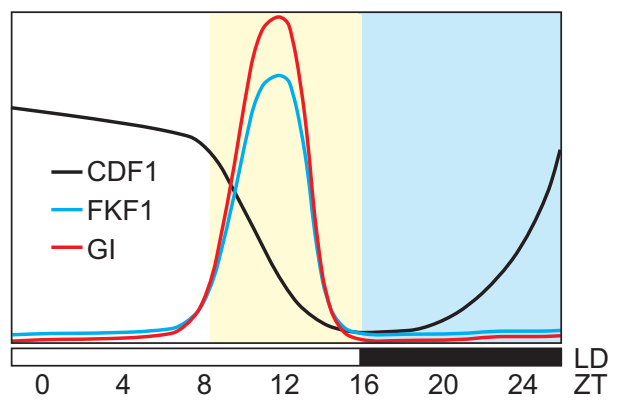

b

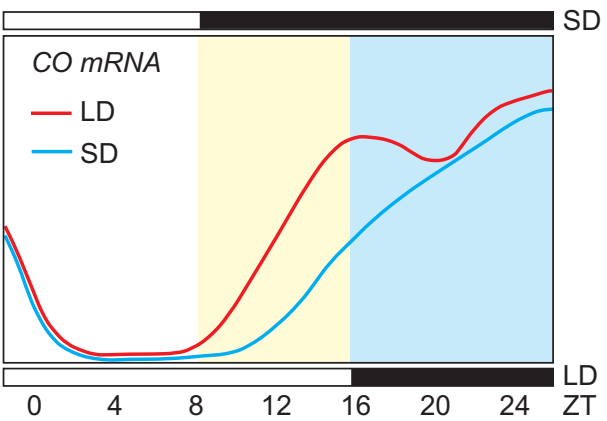

C

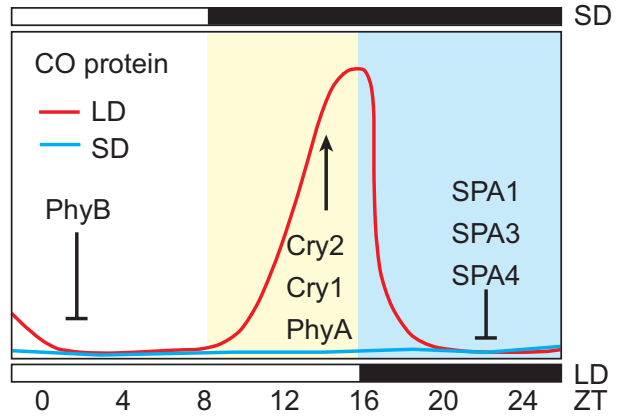

d

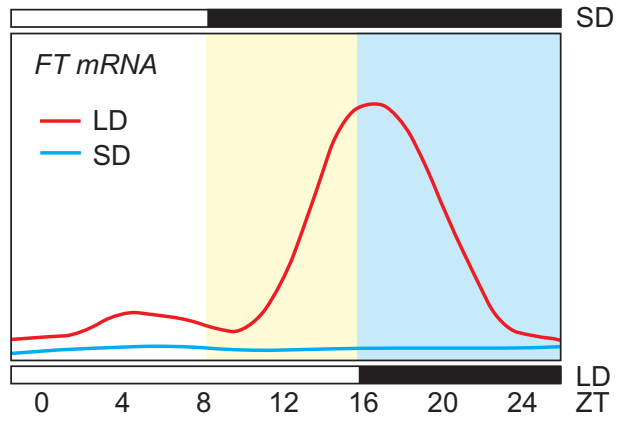




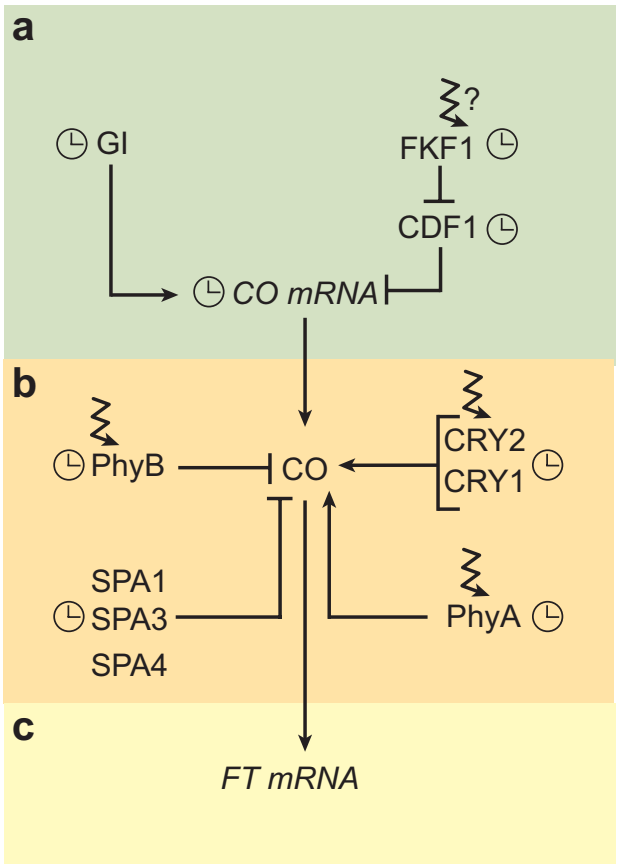

Figure 2

Network that regulates CONSTANS (CO) mRNA expression and CO protein stability. The circadian clock is a master regulator of photoperiod pathway components and associated genes. Several photoreceptor classes regulate the pathway. Clock symbols indicate that transcription of these genes is regulated by the circadian clock. Zigzag arrows indicate proteins that directly perceive light, which is more thoroughly characterized for phytochromes and cryptochromes than for FKF1. (a) Transcriptional regulation. (b) Posttranscriptional regulation. (c) CO protein accumulation results in activation of FLOWERING LOCUS T (FT) transcription. Perpendicular lines represent inhibitory interactions. Arrows represent positive interactions. GI, GIGANTEA; CDF1, Cycling DOF Factor 1; FKF1, FLAVIN-BINDING FACTOR 1, KELCH REPEAT, F-BOX PROTEIN; PhyB, PHYTOCHROME B; CRY1, CRYPTOCHROME 1, SPA1, SUPRESSOR OF PHYA-105-1.

suggested that posttranscriptional activation of CO may occur only when $C O$ mRNA is expressed in the light. Support for this model came from manipulating the circadian rhythm of $C O \mathrm{mRNA}$ expression using the toc 1-1 mutation or by altering the length of the daily cycle from $24 \mathrm{~h}$. Both of these approaches showed that if $C O$ mRNA accumulates in the light under SDs, then $F T$ expression and early flowering occur $(75,99)$.

Under LDs the peak of $C O$ mRNA abundance is broader and extends into the light (Figure 1). This response requires the
FLAVIN-BINDING, KELCH REPEAT, FBOX PROTEIN 1 (FKF1) protein. In $f k f 1$ mutants the abundance of $C O$ mRNA in the light at the end of an LD is reduced (36) (Figure 1). FKF1 encodes the F-box protein subunit of an SCF ubiquitin ligase, suggesting that FKF1 directs the degradation of substrate proteins by catalyzing their ubiquitination. FKF1 interacts with GI in vivo and light is required to stabilize their interaction (78). Thus the FKF1-GI complex might target for degradation a negative regulator of $\mathrm{CO}$ transcription and thereby increase $\mathrm{CO}$ mRNA levels at the end of the day. Consistent with this idea, FKF1 and GI transcription is also regulated by the circadian clock and their mRNA abundance peaks around the time $C O$ transcription rises (Figure 1). The transcription factor CYCLING DOF FACTOR 1 (CDF1) likely plays a part in this negative regulation of $C O$. CDF1 physically interacts with FKF1 and GI $(35,78)$, and overexpression of CDF1 from the CaMV $35 \mathrm{~S}$ promoter causes late flowering and represses $\mathrm{CO}$ transcription. HA-CDF1 expressed from the $C D F 1$ promoter accumulates only early in the day in wild-type plants but persists for longer in $f k f 1$ mutants, consistent with a role for FKF1 in the degradation of CDF1 protein. Chromatin immunoprecipitation data suggest that FKF1, GI, and CDF1 proteins bind the $\mathrm{CO}$ promoter and that degradation of CDF1 possibly takes place on the DNA at the $C O$ locus (78). However, plants in which $C D F 1$ mRNA levels were severely reduced by $C D F 1$ double-standed RNAi exhibited a weak earlyflowering phenotype and no increase in $C O$ mRNA levels (35). Thus the requirement for $\mathrm{CDF} 1$ in regulating $C O$ transcription in wildtype plants is relatively weak, perhaps because it is genetically redundant with other repressors of $C O$ transcription.

The observation that expression of $\mathrm{CO}$ mRNA during the night under SDs does not promote flowering suggested that exposure to light activates $\mathrm{CO}$ function at the posttranscriptional level. Analysis of CO:GFP fusion protein expression demonstrated that this 
activation occurs at the level of accumulation of the CO protein (92). In 35S::CO:GFP plants, GFP is detected in the nucleus when plants are exposed to light, but disappears within a few hours of shifting plants to darkness. Endogenous CO protein is below the level of detection on Western blots, but when expressed from the CaMV $35 S$ promoter, $\mathrm{CO}$ protein is easily detected. The protein accumulates to highest levels at the end of an LD and falls rapidly in abundance in the dark, whereas in these plants $C O$ mRNA is present at constant levels. Furthermore, the abundance of the protein is increased by application of a proteasome inhibitor, supporting the idea that $\mathrm{CO}$ protein is degraded via ubiquitination. These data suggest that turnover of $\mathrm{CO}$ protein is increased during the night and at the beginning of the day, but reduced at the end of the day, and therefore that posttranscriptional regulation provides an independent layer of regulation that limits $\mathrm{CO}$ activity to the end of the day (Figure 1).

The effect of light quality on CO protein levels was then tested in photoreceptor mutants carrying the $35 S:: C O$ transgene (92). These experiments indicated that PhyB is required for the degradation of the protein early in the day.

In contrast, cryptochromes, in particular CRYPTOCHROME 2 (CRY2), as well as PHYTOCHROME A (PhyA), contribute to the stabilization of the protein at the end of the day, although single mutations in these photoreceptors have a small effect on protein abundance, suggesting that the photoreceptors might be functionally redundant (92) (Figure 1). The photoreceptors PhyA, CRY2, and CRYPTOCHROME 1 (CRY1) promote CO stability, whereas the photoreceptor PHYTOCHROME B (PhyB) destablizes CO. These data are in agreement with the flowering times of photoreceptor mutants, because the cry 2 and phy $A$ photoreceptor mutants are late flowering, whereas $p h y B$ mutants are early flowering (63, 99). Finally, degradation of the CO protein likely involves the SUPPRESSOR
OF PHYA-105-1 protein (SPA1). SPA1 was previously shown to act in concert with the E3 ubiquitin ligase CONSTITUTIVE PHOTOMORPHOGENESIS 1 (COP1) to regulate photomorphogenesis. Mutations in SPA1 cause early flowering under SDs, and this phenotype is enhanced by combining mutations in related SPA genes, so that the spa1 spa3 spa4 triple mutant flowers at the same time under LDs and SDs (49). SPA proteins physically interact with $\mathrm{CO}$ both in vitro and in vivo, and mutations in $C O$ suppress the early flowering of spa 1 mutants. Also the abundance of the CO protein is markedly increased in a spa 1 spa 3 spa 4 triple mutant. These results suggest that the SPA proteins are important in mediating the degradation of the $\mathrm{CO}$ protein. Factors involved in $\mathrm{CO}$ degradation include SPA1 (SUPRESSOR OF PHYA-105-1), SPA3, and SPA4.

The analysis of the temporal regulation of CO mRNA and protein suggests that the photoperiodic flowering response in Arabidopsis is controlled by an external coincidence model similar to that originally proposed by Bünning (14) and Pittendrigh \& Minis (68). According to this model, the photoperiodic response is triggered when the product of an enzymic reaction reaches a threshold level. The abundance of the substrate of this reaction exhibits a circadian rhythm, and the enzyme that converts the substrate to the product is active in the light but reverts to an inactive state in the dark. Therefore, the photoperiodic response would only occur when exposure to light, which activates the enzyme, coincides with the peak in the circadian rhythm of the substrate. This model has striking similarities to the regulation of $\mathrm{CO}$, in which the circadian rhythm in the substrate is represented by the rhythm in $C O$ mRNA abundance, and inactivity of the enzyme in the dark is represented by the degradation of $\mathrm{CO}$ protein in darkness. Although at first sight the $C O$ system appears even simpler than the original model because it includes only one component, the reality is likely much more complex. For example, external coincidence between circadian 
Eukaryotic

CCAAT-box

binding complex:

CBF-B/CBF-C/

CBF-A or NF-YA/

$\mathrm{NF}-\mathrm{YB} / \mathrm{NF}-\mathrm{YC}$ in

animals; HAP2/

HAP3/HAP5 and

HAP4 in yeast regulation and exposure to light probably also acts on other components within the pathway (Figure 2). FKF1 binds flavin mononucleotide, the chromophore of the photoreceptor phototropin, and according to spectroscopic data FKF1 forms photointermediates similar to those formed by phototropin (36). This observation suggests that FKF1 activity is influenced by light. Furthermore, GI transcription is regulated by the circadian clock and activated by light and the GI protein requires light for the interaction with FKF1. Therefore, exposure to light can influence the activity of $G I$ at the transcriptional and posttranscriptional level $(62,78)$. Thus, although our understanding of $\mathrm{CO}$ regulation is most advanced, similar interactions between light and circadian regulation likely control the activity of multiple components in the photoperiodic pathway (Figure 2).

\section{ACTIVATION OF $F T$ TRANSCRIPTION BY CO}

In general, understanding the biochemical function of $\mathrm{CO}$ has not advanced as rapidly as understanding its regulation and general contribution to photoperiodic responses. Genetic analysis placed $F T$ downstream of $C O$ and experiments performed with a chemically inducible CO:GR fusion protein suggested that it plays a direct role in $F T$ transcriptional activation (40, 44, 47, 77, 85).

CO contains two distinct, well-defined protein domains called the B-box (Zinc finger domain) and the CCT (CONSTANS, CO-LIKE, TIMING OF CAB 1) domain (26, 70, 74). Zinc-binding B-boxes are found in many animal transcription factors (89); one or two B-boxes are usually associated with a RING and a coiled-coil domain to form the so-called tripartite motif (11), which has been implicated in protein-protein interactions rather than DNA binding. The aminoterminal B-box of $\mathrm{CO}$ is the founding member of a plant-specific B-box subvariant, which occurs either as a single or duplicated domain, often but not always in combination with a
CCT domain. $\mathrm{CO}$ and 16 related COL (COLIKE) proteins in Arabidopsis carry the combination of B-box and CCT domains $(26,74)$, whereas additional proteins contain the CCT domain but no B-boxes.

Difficulty in demonstrating direct DNA binding led to the suggestion that $\mathrm{CO}$ is recruited to DNA by an unidentified protein partner (85). As CO B-box:Gal4 DNA binding domain fusion proteins transactivate gene expression in yeast, the role of $\mathrm{CO}$ may be to add transactivation function to a protein complex (7). A recent alternative hypothesis is that $\mathrm{CO}$ requires protein partners to enhance the affinity of an otherwise weak DNA binding activity of the CCT domain. This hypothesis is based on the finding that the CCT domain of CO and several Arabidopsis or tomato COLs interact with subunits of the eukaryotic CCAAT-box binding complex $(7,94)$ and that the CCT domain shows structure and sequence homology to the sequencespecific DNA binding domain of HAP2 (94).

Metazoan CBF/NFY and yeast HAP complexes are formed by three and four distinct subunits, respectively (57). The preassembled HAP3 and HAP5 dimer recruits the structurally unrelated HAP2 subunit to the complex. None of the subunits alone can stably bind DNA, but the preassembled trimeric complex stably associates with canonical CCAAT box cis elements. Amino acid residues required for HAP2 interaction with HAP3/5 and CCAAT-element recognition are most conserved in the CCT domain. Furthermore, mutations that impair the activity of CCT domain-containing proteins affect these conserved amino acids (94).

Genetic evidence that HAP proteins regulate $F T$ transcription has been difficult to obtain because in Arabidopsis approximately 10 genes encode each of the different subunits (20, 28). Nevertheless, perturbation of subunit stoichiometry by overexpression of HAP2 or HAP3 subunits strongly delays flowering of Arabidopsis, and this effect can be counterbalanced by increasing $\mathrm{CO}$ concentration (94). 
Is FT the only gene activated by CO? Studies using 35S::CO:GR transgenic plants, in which $\mathrm{CO}$ activity can be induced with dexamethasone, initially identified that $F T$ and several other genes, including SOC1 (SUPPRESSOR OF OVEREXPRESSION OF CONSTANS), are directly activated by CO. However, expression of $\mathrm{CO}$ from the $\mathrm{CaMV}$ $35 \mathrm{~S}$ promoter in this experiment, at a higher level than in wild-type plants and in a broader set of cell types, may have led to the activation of genes that are not regulated by $\mathrm{CO}$ in wild-type plants. Microarray analysis comparing genes expressed in leaves of wild-type, $c o$, and $f t$ plants shifted from SDs to LDs identified $F T$ as the only gene whose expression was higher under LDs than under SDs in wild-type plants but not in co mutants (95). Also, an mRNA null allele of $F T(f t-10)$ apparently suppressed the early-flowering phenotype caused by overexpression of $\mathrm{CO}$ from the CaMV $35 S$ promoter (100). These experiments suggest that $F T$ is the only gene activated by $\mathrm{CO}$ and the only gene that promotes flowering downstream of CO. However, the FT-like gene, TWIN SISTER OF FT (TSF), also appears to be activated by $\mathrm{CO}$ and promotes flowering (97). So far these observations have not been completely reconciled, but they suggest that $\mathrm{CO}$ probably activates at least the expression of $F T$ and TSF in leaves (Figure 3).

\section{CLASSICAL STUDIES DEMONSTRATED THE INVOLVEMENT OF SYSTEMIC SIGNALING IN PHOTOPERIODIC FLOWERING}

Photoperiod perception takes place predominantly in expanded leaves. These leaves evolved to absorb light during photosynthesis and do so more effectively than the SAM, the site of organ formation, which is often shaded by newly formed leaves. Studies performed from the 1930s onward led to the proposal that one or more mobile signals synthesized in the leaves are transported through the phloem to the SAM and that perception of this mobile signal(s) causes the meristem to change from vegetative development to reproductive development (102). The nature of the signal was further characterized in different plant species over many years. Once induced, the synthesis and effectiveness of the leaf signal can be astonishingly persistent. In Perilla spp., successive grafting of an induced leaf to a noninduced shoot could be successfully repeated with the same leaf up to seven times over a period of three months (43). Furthermore, floral induction across interspecies grafts has been reported and long-day and short-day plants are capable of inducing plants of the other response type to flower, suggesting that the floral stimulus appears to be the same or at least functionally equivalent in both types. These experiments supported the hypothesis that a flowering hormone, termed florigen (15), or the floral stimulus, exists in plants and moves from its site of production in the source leaves through the phloem toward the SAM and potentially other sink tissues. None of the classical phytohormones appear to correspond to the definition of a universal floral stimulus, although particularly in Lolium spp. a strong argument has been made for gibberellins (GAs) acting as a systemic floral signal (42).

\section{ANALYSIS OF THE SPATIAL REGULATION OF THE PHOTOPERIODIC PATHWAY LINKS FT PROTEIN AND FLORIGEN}

The connection between the florigen hypothesis and the CO/FT module became apparent when the tissues in which $C O$ and FT act to regulate flowering were identified. In young plants, $C O$ and $F T$ are expressed in phloem companion cells, particularly in those of the distal minor veins of source leaves $(3,86)$. For $F T$ this seems to be the only site of expression; however, because of the difficulty in detecting the endogenous transcript by in situ hybridization, these data rely only on promoter reporter gene studies and therefore
Florigen:

compound produced in the leaf that moves through the phloem to the shoot apex to induce flowering 

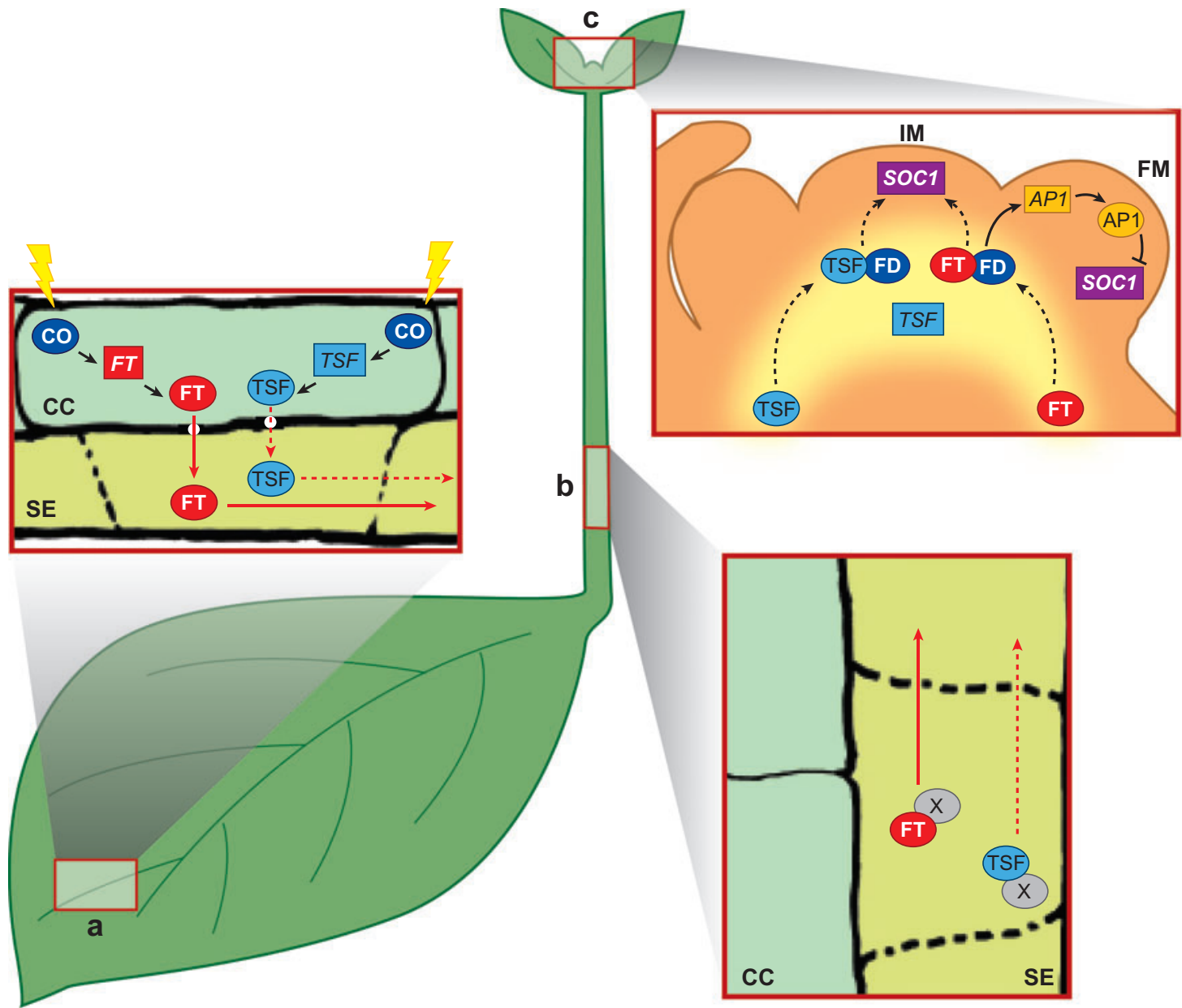

Figure 3

FLOWERING LOCUS T (FT) as a systemic signal. (a) Coincidence of CONSTANS (CO) mRNA accumulation and light at the end of long days (LDs) stabilizes the $\mathrm{CO}$ protein. $\mathrm{CO}$ then allows transcription of FT and TWIN SISTER OF FT (TSF) in the phloem companion cells within the distal part of the leaf. FT protein is uploaded into the sieve elements either by diffusion through plasmodesmata or by an unidentified active transport mechanism (white circle). The similarity between FT and TSF proteins suggests they behave similarly, but no evidence for movement of the TSF protein has been presented.

(b) Long-distance transport of FT toward sink tissues occurs in the phloem translocation stream. FT may associate with other as yet unknown factors (X) during this step. (c) FT unloading from the phloem and transport within the apex probably involves cell-to-cell transport through plasmodesmata. The yellow area indicates a possible gradient of FT and TSF protein distribution in the shoot apical meristem (SAM). Whether diffusion or directed active transport is involved is unclear. Induction of SUPPRESSOR OF OVEREXPRESSION OF CONSTANS (SOC1) is the first detectable event in the inflorescence meristem (IM) and depends on the presence of FT and the bZIP transcription factor FLOWERING LOCUS D (FD), but whether these directly activate SOC1 transcription is unknown. FT and FD interact physically and the complex is directly involved in APETALA 1 (AP1) transcriptional activation, which occurs during the formation of the first floral bud. AP1 directly represses SOC1 in the floral meristem (FM). TSF protein might follow the same systemic path toward the SAM as does FT. In addition, promoter TSF::GUS fusions indicate that the TSF transcript could be directly produced in cells at the periphery of the SAM. CC, companion cells; SE, sieve elements; boxes, mRNA; circles, protein; solid black arrows, experimentally confirmed interconnection; dotted arrows, inferred interconnection. 
require further validation (86). In contrast to $F T, C O$ mRNA is found in the apical regions above the protophloem and expression is less restricted to the phloem tissue in younger leaves $(3,82)$. However, $\mathrm{CO}$ protein stability is tightly regulated (see above) and studies with $C O:: C O: G F P$ fusions indicated that the spatial pattern of $\mathrm{CO}$ protein is restricted to the phloem (3).

Misexpression of $\mathrm{CO}$ from heterologous promoters and grafting experiments placed $\mathrm{CO}$ upstream of a leaf-borne transmissible signal. Thus, expression of $C O$ driven by the promoter of $S U C 2$ in the companion cells throughout the phloem system or by the GAS1 promoter, which is more restricted to the companion cells of the minor veins, generates a graft-transmissible signal that is sufficient to cause a $c 0$ mutant scion to flower $(3,5)$. In contrast, expression of $\mathrm{CO}$ in the SAM does not promote flowering (3). Conversely, FT causes early flowering when expressed in the phloem or the SAM, and expression of FT in either of these tissues promotes the floral transition even in the absence of functional $\mathrm{CO}$ (3). This observation confirms that $C O$ acts upstream in the signaling cascade of FT and of the transmissible signal. Indeed, these experiments indicate that the signal must reside downstream of $F T$ transcription $(3,86)$.

Although FT is expressed only in the vascular tissue (86), the known biochemical function of FT is in the meristem $(1,95)$, as is described in detail below. This discrepancy between the spatial pattern of FT mRNA expression and the location at which the protein acts provided evidence that a product of FT might represent the mobile signal. Two general models emerged to explain the relationship between $F T$ and florigen. A direct model proposed that $F T$ encodes florigen, so that either FT mRNA or protein (or both) move from source leaves to the meristematic tissue. Alternatively, an indirect or relay model proposed that FT activates a transmissible signal in the leaf, and that this moves to the meristem, where it activates expression of $F T$ or an FT-like gene. The involvement of an $F T$-like gene would be more plausible because FT expression has not been detected at the meristem.

The first experiments performed to test movement of an FT product focused on the FT mRNA. Experiments describing movement of FT mRNA from the leaf to the meristem using a fusion of a promoter from a heat shock-inducible gene (from soybean Gmbsp 17.6L) to $F T$ were subsequently retracted (9). Furthermore, FT mRNA movement was excluded on the basis of grafting experiments performed in tomato, where mutations in the FT ortholog SINGLE FLOWER TRUSS (SFT) cause late flowering (64). Tomato plants overexpressing $S F T$ are early flowering. Grafting a 35S::SFT donor to an sft recipient shoot corrected the mutant phenotype of the recipient shoot. Similarly, 35S::SFT donors could rescue the late-flowering phenotype of Maryland Mammoth tobacco plants (51, 52). These experiments indicated that the systemic signal must cross the graft junction between these shoots, but careful PCR analysis using RNA of the recipient shoot did not detect SFT mRNA that had crossed the graft junction. A similar result was obtained with grafted $\mathrm{Ara}$ bidopsis plants, in which no movement of FT mRNA could be detected across graft junctions (18). FT mRNA requirement in the apex was also excluded by expressing artificial miRNAs targeted against $F T$ in the SAM and the phloem. Expression of artificial miRNAs in the SAM did not alter flowering time, whereas when expressed in the phloem they phenocopied the ft mutant (59). Taken together these experiments argue against longdistance movement of FT mRNA and against a requirement for the mRNA in the SAM.

In contrast, several results support movement of the FT protein. Expression of FT:GFP fusion proteins from the phloemspecific SUC2 promoter allowed detection of a GFP signal in the phloem and the SAM region (18), suggesting that the fusion protein can move from the phloem to the meristem. Similar results were obtained 
in rice using the rice ortholog of $F T, H d 3 a$ (87). In Arabidopsis, the fusion protein but not its mRNA moved toward sink tissue across graft junctions (18). Protein movement was further detected using FT:MYC fusion protein also expressed under the control of the phloem-specific SUC2 promoter (39). Finally, in grafted Cucurbita moschata, protein mass spectrometry was used to show that an FT-like protein moved through the phloem system across graft junctions and that this correlated with flowering (53). Taken together these experiments seem to convincingly demonstrate that FT protein can move long distances through the phloem system and that this is associated with floral induction (Figure 3).

However, diffusion of small proteins expressed in companion cells into the sieve element and subsequent transport toward sink tissues may be a general phenomenon, such that movement of a small $(20 \mathrm{kDa})$ protein such as FT may be the expected result $(37,56,66)$. Therefore, demonstrating movement of the FT protein is not sufficient to prove that it acts as a transmissible signal, but rather evidence that movement of FT protein is necessary for flowering to occur is required. Such evidence was provided by several experiments. When expressed in the phloem, FT protein fused to a fluorescent protein is impaired in its ability to complement $f t$ mutations. Although FT:GFP complements an $f t$ mutation when expressed in the SAM or in the major veins from the SUC2 promoter, its expression in the minor veins of the leaves from the GAS1 promoter does not complement the mutation (18). This is in contrast to GAS1::FT, which does complement $f t$. Furthermore, GAS1::FT:GFP plants exhibit altered gene expression patterns in the leaves similar to those caused by $35 S:: F T$ (88). Therefore FT:GFP is active in the leaves of GAS1::FT:GFP plants. These experiments suggested that FT movement from the minor veins is required to promote flowering, and that this movement is impaired in GAS1::FT:GFP plants (18).
Similarly, FT protein fused to three consecutive YFP proteins did not induce earlier flowering of wild-type plants if expressed from the $S U C 2$ promoter, but did if expressed ubiquitously from the CaMV $35 S$ promoter. This experiment suggests that FT:3xYFP is biochemically active but cannot move from the phloem when expressed from the SUC2 promoter. Because this fusion protein also contained a viral peptidase recognition site, free FT protein could be cleaved from the fusion protein in the presence of the viral peptidase. Expression of the viral peptidase from the $S U C 2$ promoter released free FT protein, which induced earlier flowering of wild-type plants (59). This result suggests that movement of free FT but not FT:3xYFP induces early flowering of these plants.

Finally, FT protein was engineered for efficient targeting to the nucleus and a MYC epitope-tag was added (MYC:NLS:FT) (39). Expression of this fusion protein from the SUC2 promoter in an $f t-10$ mutant did not affect the flowering time of the mutant, whereas when expressed from the CaMV $35 \mathrm{~S}$ promoter it caused extreme early flowering. SUC2::MYC:FT ft-10 plants were early flowering and MYC:FT protein could be detected beyond the vascular tissue in the meristem region, whereas the late flowering of SUC2::MYC:NLS:FT ft-10 plants correlated with reduced movement of the protein beyond the phloem (39). Taken together, all these experiments based on different approaches provide evidence that movement of FT protein is required for the induction of flowering and that there is no need to postulate an intermediate signal acting between FT activity in the leaf and flowering at the SAM.

Although the experiments described above demonstrate that FT protein movement is required for flowering, they do not unequivocally show that FT protein and florigen are equivalent. For example, a second signal, perhaps induced by expression of FT in the leaf, might move along with $\mathrm{FT}$ protein. If this second signal were required to optimize movement of FT or to increase the efficiency of 
the system, then its requirement might be bypassed by direct expression of $F T$ in the meristem. Therefore, the possibility that FT protein acts together with a second mobile component cannot be formally excluded, and active florigen could still be a mixture of substances of which FT protein is only a part.

\section{THE ROLE OF FT IN THE SHOOT APICAL MERISTEM}

The developmental program that initiates flower development occurs at the apical meristem after synthesis of FT in the leaves and its transport through the phloem system, but what is the function of FT at the SAM? A breakthrough in this area came from the demonstration that FT interacts in the yeast two-hybrid system with the bZIP transcription factor FLOWERING LOCUS D (FD) $(1,95)$. Furthermore, mutations in $F D$ cause late flowering (47), and $f d$ mutations suppress the early flowering of $35 S:: F T$ plants $(1,95)$. $F D$ mRNA is strongly expressed at the SAM, suggesting that this is the major site of FD action, although it is also present at the root meristem and at lower levels throughout the plant $(1,95)$ (Figure 4).

The FT/FD heterodimer is involved in the activation of the floral meristem identity genes APETALA 1 (AP1) and FRUITFUL (FUL) at the shoot apex. Occurrence of $A P 1$ at the apex is strongly delayed in $f d$ mutants (95) and abolished in either fd lfy or ft lfy double mutant plants, indicating that the FT/FD complex acts redundantly with LFY to activate $A P 1(1,95)$. Whereas lfy mutant plants form abnormal flowers, introduction of either $f d$ or $f t$ as a second mutation causes the resulting plants to form leaves instead of flowers (1, $76,95)$. Furthermore, $F D$ overexpression under the control of the $C a M V 35 S$ promoter causes ectopic expression of $A P 1$ and FUL in leaves of LD-grown but not SD-grown plants,

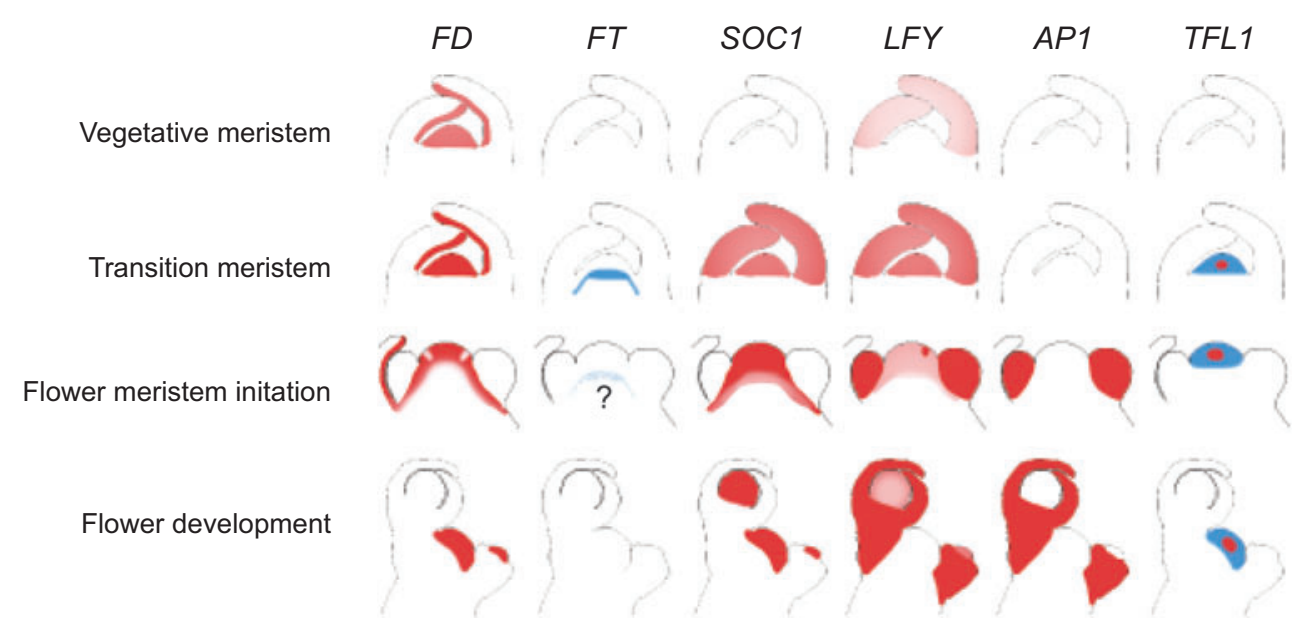

Figure 4

Dynamics of gene expression in the shoot apical meristem upon floral transition. From top to bottom: progression of the apical meristem from a fully vegetative state (vegetative meristem) to a reproductive state (flower development). Two intermediate stages are shown: the transition meristem stage, where morphological changes are not yet visible but induction is taking place, and the flower meristem initiation stage, where the first flower primordia are arising on the flanks of the inflorescence meristem. The mRNA (red) and protein (blue) patterns of key regulators of floral transition are shown. The varying intensity of the color accounts for the expression level of the gene. The question mark referring to FLOWERING LOCUS T $(F T)$ in later stages indicates that the pattern is inferred. Abbreviations: $F D$, FLOWERING LOCUS D; SOC 1, SUPPRESSOR OF OVEREXPRESSION OF CONSTANS 1; LFY, LEAFY; AP1, APETALA 1; TFL1, TERMINAL FLOWER 1. 
suggesting that FT is required in leaf tissue for this expression to occur $(1,95)$. Similarly, $C a M V 35 S$ promoter-driven overexpression of $F T$ causes ectopic expression of $A P 1, F U L$, and SEP3 in leaves, which is strongly reduced if the transgene is expressed in an $f d$ mutant background (88). These observations are consistent with the idea that the FT/FD heterodimer regulates $A P 1, F U L$, and SEP3 expression in the meristem, and that overexpression of FT or FD in the leaves causes ectopic expression of the downstream genes.

FT/FD probably activates $A P 1$ by directly binding to its promoter, presumably via the DNA binding domain of FD. A C-box, a cis element bound by bZIP factors, is present in a functionally important region of the $A P 1$ promoter in close proximity to LFY binding sites (95). The role of FT in the heterodimer is currently unclear, but it might provide a coactivator function to the FT/FD complex, and this is supported by a chromatin immunoprecipitation experiment that detected FT associated with the AP1 promoter (95). Alternatively, FT might be necessary for posttranslational modification of FD, thereby activating it or targeting it to the nucleus. A putative calcium-dependent protein kinase target site in FD appears to be required for the interaction with FT in yeast two-hybrid assays, supporting the idea that posttranslational modification regulates the interaction (1).

Robust AP1 expression is detectable at the SAM four days after a shift from SD to LD in Landsberg erecta, at a time when the first stage 1 floral bud is visible (Figure 4). By this stage production of the FT signal in the leaves is not required any longer, and the meristem is fully committed to flower independently of FT expression in the leaves (18). Therefore, the first molecular event controlled by FT at the SAM upon floral induction is unlikely to be the activation of $A P 1$. In contrast, induction of SOC1 expression in the SAM is detected much earlier than AP1 expression, approximately $16 \mathrm{~h}$ after a shift from SD to LD and prior to macroscopic changes at the meristem $(12,80)$ (Figure 4). Induction of SOC1 is strongly delayed in either $f t$ or $f d$ mutant plants, so that FT and FD are required for the earliest marker of floral induction in the meristem that is currently available (80), consistent with gene activation by FT/FD as the earliest step in the floral transition that occurs at the meristem.

SOC1 acts as a floral integrator and is activated by FT-dependent and FT-independent pathways $(50,65,77,100)$. Mutations in SOC1 cause late flowering under LDs or SDs (12). So far, there has not been a report on the identification of direct SOC1 target genes, so the order of events after SOC1 activation is unclear. However, the inverse correlation of SOC1 and AP1 expression (Figure 4) may be indicative of a complex feedback loop relationship between different FT/FD target genes (54).

\section{FT-RELATED GENES IN ARABIDOPSIS}

A small family of six FT-like genes exists in Arabidopsis, and these genes might have related functions in floral induction. The proteins encoded by these genes contain a phosphatidylethanolamine binding domain (PEPB) (16). The physiological function of PEPB proteins is widely studied in animals in which they are proposed to act in signaling cascades via protein-protein interactions (16). In Arabidopsis the PEPB family comprises, in addition to FT and TSF, BFT (BROTHER OF FT), ATC (ARABIDOPSIS THALIANA RELATIVE OF CENTRORADIALIS), MFT (MOTHER OF FT AND TFL1), and TFL1 (TERMINAL FLOWER 1) (13, 61, 97, 101).

Of these proteins TSF is the most similar to FT, such that the proteins are $81.3 \%$ identical. FT and TSF show similar, but not overlapping, expression patterns in the phloem and significant homology is detected in the proximal parts of their promoters. However, in contrast to FT, TSF is also expressed at low levels in the basal part of the apical meristem. Expression analyses confirmed that, similar to 
$F T, T S F$ responds rapidly to varying levels of $\mathrm{CO}$ and is repressed by FLC and EARLY BOLTING IN SHORT DAYS (EBS) (97). In contrast to FT, TSF expression is not increased in tfl2/lhp 1 mutants, although chromatin immunoprecipitation on chip data suggest TFL2/LHP1 is associated with the TSF locus (90). At least in young plants, TSF is expressed at a low level, possibly because of the presence of large retrotransposon and repetitive sequence insertions at the $3^{\prime}$ end of the gene. The tsf mutation has only a minor effect on flowering time under LDs in the presence of an active $F T$ gene, but $f t t s f$ double mutants show an additive phenotype, indicating genetic redundancy between the genes (97). The spatial requirement for $F T$ and TSF mRNA was analyzed using an artificial microRNA directed against both genes (59). Transgenic plants expressing the amiRFT/TSF in the phloem phenocopied the ft tsf double mutant, but flowering time was not affected when amiR-FT/TSF was expressed in the $F D$ domain. This experiment indicates that TSF mRNA, like $F T$ mRNA, is active in the companion cells of the phloem and is not required in the meristem. Taken together these data indicate that TSF could regulate flowering by a mechanism similar to that proposed for FT, but so far it has not been reported whether TSF protein can move to the SAM along with FT (Figure 3).

TFL1 has an antagonistic effect on FT in the regulation of flowering. Loss-of-function tfl1 mutant plants flower early independently of day length and form a terminal flower, similar to FT-overexpressing plants $(13,40,44)$. Conversely, 35S::TFL1 plants flower late in LDs and have a prolonged inflorescence phase in which cauline leaves rather than flowers are produced, a phenotype related to that of $f t \mathrm{mu}-$ tants (71). Paradoxically, the TFL1 transcript is upregulated in the inflorescence meristem through activation of $C O$ (82). A current hypothesis is that TFL 1 acts as a competitor of FT in the apex to prevent FT from converting the SAM into a floral meristem (2). Consistent with this hypothesis, whereas TFL1 mRNA is restricted to the center of the SAM, the TFL1 protein moves beyond its mRNA expression domain and spreads into the entire meristem (17) (Figure 4). Although a mechanism of reciprocal competitive binding of FT and TFL1 to FD has been proposed as the mechanism underlying this function, at present it is not clear whether the TFL1 and FD proteins can physically interact, because two reports have shown contradictory yeast two-hybrid results $(1,95)$. A reciprocal single amino acid exchange of FT and TFL1 is sufficient to reverse the function of these proteins (29). The homologs most similar to TFL1 are BFT and $A T C$, but their roles in plant development are unclear. No mutant alleles of $B F T$ have been described so far, and atc mutants do not show any obvious alteration in flowering time or flower development (61).

The third class of FT-like protein is represented by MFT (101). MFT is equally related to FT and TFL1 and, at the critical position proposed to distinguish FT and TFL1, MFT has an amino acid different from both. $M F T$ does not belong to the FT/TSF category; nevertheless, overexpression of $M F T$ can also cause slightly early flowering in LDs (101), although mutations in MFT do not have a perceptible effect on flowering. Nevertheless, to fully understand how these genes contribute to the systemic signaling and meristem functions currently ascribed to FT, it will be important to describe the patterns of expression of each gene, to systematically combine null alleles of the different family members, and to determine how these combinations alter flowering time.

\section{FLOWERING OF ARABIDOPSIS UNDER SHORT DAYS}

Arabidopsis is a facultative long-day plant and therefore eventually flowers under SDs. Under LDs $f t$ mutants are late flowering, but reports on the effects of FT/TSF under SDs differ. For example, whereas Michaels and colleagues (60) found no effect of $f t$ or $t s f$ mutations under SDs, Yamaguchi and coworkers
TERMINAL

FLOWER 2/LIKEHETERO-

CHROMATIN

PROTEIN 1

(TFL2/LHP1): a

repressor of genes that are regulated by the Polycomb pathway in Arabidopsis 
(97) found an effect of tsf and a strong enhancement in the ft tsf double mutant $(60,97)$. Nevertheless, even in the absence of both FT and TSF, flowering does occur under SDs, indicating that absence of the systemic signal represented by FT/TSF can eventually be overcome under SDs.

An attractive possibility is that an alternative pathway promotes flowering in the absence of FT/TSF and under SDs. Genetic data suggest a major role for GA in controlling flowering of Arabidopsis under SDs (96). The ga1-3 mutation, which strongly impairs GA biosynthesis, prevents flowering under SDs and strongly enhances the 102 mutation under LDs, so that the co2 ga1-3 double mutant never flowers under these conditions (72). GA may therefore compensate for the reduced effect of the FT system on SD-grown plants and $c o$ mutants, and GA does accumulate at the meristem of Arabidopsis during the transition to flowering under SDs (21). In Lolium GA was proposed to represent a systemic signal that induces flowering at the apex, and GA could represent a second signal in Arabidopsis that acts in parallel to the FT system and is not as strongly regulated by photoperiod (42).

\section{CONSERVATION OF THE CO/FT MODULE AND ITS REGULATION IN OTHER SPECIES}

Homologs of the $C O$ and $F T$ genes have been isolated from many monocotyledonous and dicotyledonous species $(26,33,41,45,55,58$, $69,73,81,91,98)$. In particular, the function of FT as a promoter of flowering appears to be remarkably conserved in all species tested in detail. Overexpression of $F T$ homologs causes extreme early flowering in the dicotyledonous plants poplar $(10,33)$, tomato, tobacco (51), and Pharbitis nil (31) as well as in the monocotyledonous plant rice (45). If FT directly encodes the floral stimulus, as discussed above, then this would be consistent with the physiological data suggesting that at least in some cases different plant species produce the same systemic signal. Furthermore, FT mRNA abundance is increased in response to exposure to photoperiods that induce flowering in barley and rice as well as Arabidopsis (30, $85,91,99)$. However, in the day-neutral plant tomato, expression of the FT ortholog SFT is not regulated by photoperiod, although overexpression of SFT promotes early flowering and $s f t$ mutations delay flowering (52). These observations indicate that regulation of $F T$ expression by photoperiod through the activity of CO homologous proteins is likely to be highly conserved in plants as distantly related as Arabidopsis and rice, but that this connection can be severed in photoperiod-insensitive plants such as tomato.

Activation of $C O$ under LDs can be explained by an external coincidence model, as described above. However, in the short-day plant rice, the regulation of the FT ortholog is reversed so that its transcription is activated under SDs and repressed under LDs (45). Elegant genetic experiments based on natural genetic variation for photoperiod response in rice, isolation of induced mutations, and construction of transgenic plants demonstrated that the core photoperiod pathway is conserved and promotes flowering under SDs. In rice the HEADING DATE 1 (Hd1) locus encodes the $C O$ ortholog (98) and Hd3a encodes an FT homolog (45). Hd3a plays a role similar to that of FT in Arabidopsis, so that $H d 3 a$ mRNA levels are higher under SDs than under LDs, Hd3a loss-of-function alleles delay flowering under SDs, and overexpression of $\mathrm{Hd} 3 \mathrm{a}$ causes early flowering (45). However, the role of $H d 1$ in rice is more complex than the role of $C O$ in Arabidopsis, because $H d 1$ both promotes flowering and $H d 3 a$ expression under inductive SDs and delays flowering and represses $H d 3 a$ expression under noninductive LDs, whereas in Arabidopsis $\mathrm{CO}$ only promotes flowering under inductive LDs (98) (Figure 5). How does $H d 1$ have opposite effects on $\mathrm{Hd} 3 \mathrm{a}$ expression under LDs and SDs? The repression of $H d 3 a$ expression under LDs could be explained by an external coincidence model similar to that proposed 
for Arabidopsis. According to this model, under LDs $H d 1$ expression coincides with exposure of plants to light, leading to the modification of $\mathrm{Hd} 1$ protein and to the repression of $H d 3 a$ expression. In contrast under SDs, $H d 1 \mathrm{mRNA}$ accumulates only during the night, and in a dark-synthesized form, the $\mathrm{Hd} 1$ protein would activate $H d 3 a$ transcription and thereby induce flowering. Although these results provide a convincing model for how flowering of rice responds to short photoperiods, the response of other short-day plants might be controlled by different mechanisms. Recent evidence suggests that flowering of Pharbitis nil, a classical short-day model species for physiological experiments, is controlled by a circadian rhythm set by dusk that induces Pharbitis nil FT (PnFT) expression only if the night is sufficiently long (31) (Figure 5). The role of $\mathrm{PnCO}$ in activation of $P n F T$ remains unclear. These experiments suggest that Pharbitis measures day length by a different mechanism than that of rice.

Analysis of the CO/FT system in poplar provided evidence for the importance of these genes in adaptation to growth at different latitudes. In poplar, the FT ortholog PnFT1 has important functions in bud dormancy as well as flowering $(10,33)$. In poplar, growth terminates in autumn and bud dormancy is initiated. This is a photoperiodic response induced by exposure to SDs during autumn, and in wild-type plants PnFT1 expression is reduced on exposure to SDs. Transgenic poplar plants overexpressing PnFT1 do not terminate growth on exposure to SDs, whereas those with reduced $P n F T 1$ expression are more sensitive to SDs. Böhlenius and colleagues (21) then tested whether the day length recognized as an SD in the regulation of PnFT1 expression differed between poplar accessions, and whether this was related to the timing of $\mathrm{PnCO}$ expression. They studied four accessions collected from locations extending from Germany at $51^{\circ} \mathrm{N}$ to northern Sweden at $63^{\circ} \mathrm{N}$. In day lengths of 17,19 , and 21 $\mathrm{h}$ they observed that $\mathrm{PnCO}$ is expressed at an earlier phase in the southern accessions.

\section{Arabidopsis}
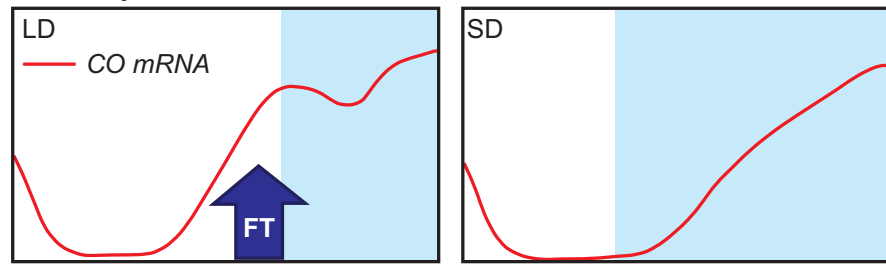

\section{Rice}
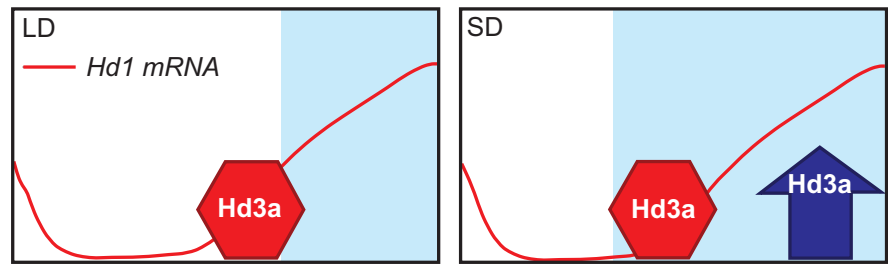

\section{Pharbitis}
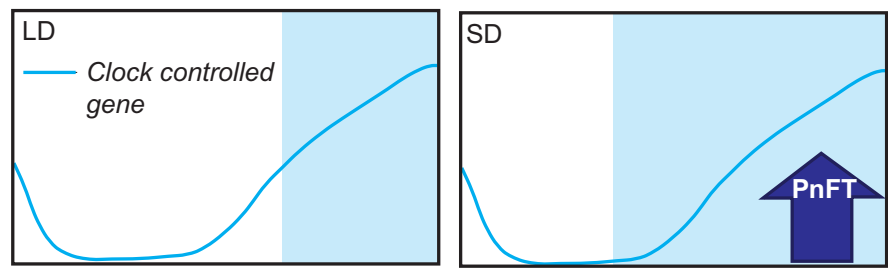

Figure 5

Regulation of $F T$ mRNA expression by day length in different species. In Arabidopsis the expression of $C O$ at the end of a LD and the light-induced stabilization of the $\mathrm{CO}$ protein cause activation of $F T$ transcription. Under $\mathrm{SD}$ the $\mathrm{CO}$ protein does not accumulate, $F T$ transcription is not activated, and flowering is delayed. In rice the photoperiodic response is reversed so that the CO ortholog HEADING DATE 1 (Hd1) activates HEADING DATE $3 a(H d 3 a)$ transcription under SD but represses it under LD. The effect of $\mathrm{Hd} 1$ on $H d 3 a$ activation is proposed to be due to light-induced modification of Hd1. According to this model, when rice plants are exposed to light the $\mathrm{Hd} 1$ protein is synthesized in a form that represses $H d 3 a$ transcription, whereas in a dark-synthesized form the same protein acts as a promoter of Hdza expression. In Pharbitis PnFT transcription is induced under SD, when the rhythm in the activity of a clock-controlled gene (CCG) reaches its peak of expression during the long night. In contrast, during LDs $P n F T$ does not accumulate because expression of the CCG is suppressed by light at dawn and never reaches a critical threshold sufficient for PnFT induction. White areas denote light, blue areas denote darkness. The blue arrows represent transcriptional activation of the gene named in the arrow. The red hexagons represent transcriptional repression of $H d 3 a . F T$, FLOWERING LOCUS T; CO, CONSTANS; SD, short day; LD, long day.

Under 19-h day lengths, PnCO mRNA expression coincides with exposure of plants to light for the two most-southern accessions but not for the two northern accessions and $P n F T$ is expressed under these conditions for the southern accessions but not the northern 
accessions. Northern accessions recognize longer day lengths as SDs and therefore induce bud dormancy earlier in the autumn in anticipation of the earlier onset of winter conditions, and this response appears to be adapted to the latitude in which poplar accessions grow through modification of the timing of $\mathrm{PnCO}$ expression and the consequent expression of $P n F T$.

\section{PERSPECTIVES}

Tremendous progress has been made in recent years in understanding the basis of florigen and the control of its expression by photoperiod (see above). However, major questions remain to be solved both in understanding the mechanistic basis of the system in the Arabidopsis model and in determining how variation in the system confers the diversity in flowering behaviors observed in nature. Understanding long-distance signaling by FT crucially requires determining whether FT protein is sufficient for this process and acts alone or whether it requires other molecules that are transported along with FT. Similarly, little is known of the mechanisms by which the protein is transported through the phloem and loaded into the meristem. We do not know in which cells FT first acts to promote the earliest steps in floral induction nor the nature of the first signaling steps that are initiated by the arrival of FT protein.

Although the core photoperiod pathway appears to be widely conserved, the broader context in which the photoperiodic response functions is likely to differ significantly in other angiosperm systems. For example, the intersection between photoperiod response and pathways controlling other environmental responses appears not to be conserved. In Arabidopsis the vernalization and photoperiod responses appear to be independent and converge on the regulation of transcription of $F T$ and other floral integrators. However, transcription of the wheat VERNALIZATION 2 gene, which encodes a repressor of flowering that plays a central role in the vernalization response, is reduced either by exposure to vernalization or by exposure to noninductive SDs (19). Such observations suggest that in other species environmental responses that influence flowering time are likely to intersect with the photoperiod pathway and regulate $F T$ transcription in ways that could not be predicted from the analysis of Arabidopsis.

Finally, time of flowering of widely used summer annual accessions of Arabidopsis such as Landsberg erecta and Columbia seems to be determined largely by whether $F T$ is expressed. Within 1 day of inducing FT expression in the leaves the mRNAs of genes associated with flowering are detected at the meristem, and within three days Landsberg erecta plants are stably committed to flower. Such observations indicate that regulatory steps in the meristem do not play a large part in determining the flowering time of these accessions, but rather that the meristem response is determined by the timing of FT expression in the leaves. However, this cannot be the case in all plants. For example, in perennials different meristems on the same plant respond differently to floral induction, so that some remain vegetative, whereas others are induced to form flowers. Such polycarpic behavior suggests either the existence of mechanisms in the meristem to regulate responsiveness or that leaf-derived signals such as FT are transported differently to particular meristems. The nature of such processes will be elucidated by future experiments and will add to the surprises this beautiful system has given us during the past 70 years.

\section{DISCLOSURE STATEMENT}

The authors are not aware of any biases that might be perceived as affecting the objectivity of this review. 


\section{ACKNOWLEDGMENTS}

The laboratory of G.C. is supported by the Max Planck Society through a core grant and work on systemic signaling is partly funded by the Deutsche Forschungsgemeinschaft through SFB 572 .

\section{LITERATURE CITED}

1. Abe M, Kobayashi Y, Yamamoto S, Daimon Y, Yamaguchi A, et al. 2005. FD, a bZIP protein mediating signals from the floral pathway integrator $\mathrm{FT}$ at the shoot apex. Science 309:1052-56

2. Ahn JH, Miller D, Winter VJ, Banfield MJ, Lee JH, et al. 2006. A divergent external loop confers antagonistic activity on floral regulators FT and TFL1. EMBO 7. 25:605-14

3. An H, Roussot C, Suarez-Lopez P, Corbesier L, Vincent C, et al. 2004. CONSTANS acts in the phloem to regulate a systemic signal that induces photoperiodic flowering of Arabidopsis. Development 131:3615-26

4. Ausin I, Alonso-Blanco C, Martinez-Zapater JM. 2005. Environmental regulation of flowering. Int. 7. Dev. Biol. 49:689-705

5. Ayre BG, Turgeon R. 2004. Graft transmission of a floral stimulant derived from CONSTANS. Plant Physiol. 135:2271-78

6. Baurle I, Dean C. 2006. The timing of developmental transitions in plants. Cell 125:65564

7. Ben-Naim O, Eshed R, Parnis A, Teper-Bamnolker P, Shalit A, et al. 2006. The CCAAT binding factor can mediate interactions between CONSTANS-like proteins and DNA. Plant 7. 46:462-76

8. Bernier G. 1988. The control of floral evocation and morphogenesis. Annu. Rev. Plant Physiol. Plant Mol. Biol. 39:175-219

9. Bohlenius H, Eriksson S, Parcy F, Nilsson O. 2007. Retraction. Science 316:367

10. Bohlenius H, Huang T, Charbonnel-Campaa L, Brunner AM, Jansson S, et al. 2006. $\mathrm{CO} / \mathrm{FT}$ regulatory module controls timing of flowering and seasonal growth cessation in trees. Science 312:1040-43

11. Borden KL, Campbelldwyer EJ, Carlile GW, Djavani M, Salvato MS. 1998. Two RING finger proteins, the oncoprotein $\mathrm{PML}$ and the arenavirus $\mathrm{Z}$ protein, colocalize with the nuclear fraction of the ribosomal $\mathrm{P}$ proteins. F. Virol. 72:3819-26

12. Borner R, Kampmann G, Chandler J, Gleissner R, Wisman E, et al. 2000. A MADS domain gene involved in the transition to flowering in Arabidopsis. Plant 7. 24:591-99

13. Bradley D, Ratcliffe O, Vincent C, Carpenter R, Coen E. 1997. Inflorescence commitment and architecture in Arabidopsis. Science 275:80-83

14. Bünning E. 1936. Die endogene Tagesrhythmik als Grundlage der photoperiodischen Reaktion. Ber. Dtsch. Bot. Ges. 54:590-607

15. Chailakhyan M. 1937. Gormonal'naya Teoriya Razvitiya Rastenii. Moscow: Akad. Nauk SSSR

16. Chardon F, Damerval C. 2005. Phylogenomic analysis of the PEBP gene family in cereals. 7. Mol. Evol. 61:579-90

17. Conti L, Bradley D. 2007. TERMINAL FLOWER1 is a mobile signal controlling Arabidopsis architecture. Plant Cell 19:767-78

18. Corbesier L, Vincent C, Jang S, Fornara F, Fan Q, et al. 2007. FT protein movement contributes to long-distance signaling in floral induction of Arabidopsis. Science 316:1030 33 
19. Dubcovsky J, Loukoianov A, Fu D, Valarik M, Sanchez A, Yan L. 2006. Effect of photoperiod on the regulation of wheat vernalization genes VRN1 and. Plant Mol. Biol. 60:469-80

20. Edwards D, Murray JA, Smith AG. 1998. Multiple genes encoding the conserved CCAATbox transcription factor complex are expressed in Arabidopsis. Plant Physiol. 117:1015-22

21. Eriksson S, Böhlenius H, Moritz T, Nilsson O. 2006. GA4 is the active gibberellin in the regulation of LEAFY transcription and Arabidopsis floral initiation. Plant Cell 18:2172-81

22. Evans LT. 1971. Flower induction and the florigen concept. Annu. Rev. Plant Physiol. 22:365-94

23. Fowler S, Lee K, Onouchi H, Samach A, Richardson K, et al. 1999. GIGANTEA: a circadian clock-controlled gene that regulates photoperiodic flowering in Arabidopsis and encodes a protein with several possible membrane-spanning domains. EMBO 7. 18:467988

24. Garner WW, Allard HA. 1920. Effect of the relative length of day and night and other factors of the environment on growth and reproduction in plants. F. Agric. Res. 18:553-606

25. Garner WW, Allard HA. 1923. Further studies on photoperiodism, the response of plants to relative length of day and night. F. Agric. Res. 23:871-920

26. Griffiths S, Dunford RP, Coupland G, Laurie DA. 2003. The evolution of CONSTANSlike gene families in barley, rice, and Arabidopsis. Plant Physiol. 131:1855-67

27. Guo H, Duong H, Ma N, Lin C. 1999. The Arabidopsis blue light receptor cryptochrome 2 is a nuclear protein regulated by a blue light-dependent post-transcriptional mechanism. Plant 7. 19:279-87

28. Gusmaroli G, Tonelli C, Mantovani R. 2002. Regulation of novel members of the Arabidopsis thaliana CCAAT-binding nuclear factor Y subunits. Gene 283:41-48

29. Hanzawa Y, Money T, Bradley D. 2005. A single amino acid converts a repressor to an activator of flowering. Proc. Natl. Acad. Sci. USA 102:7748-53

30. Hayama R, Coupland G. 2003. Shedding light on the circadian clock and the photoperiodic control of flowering. Curr. Opin. Plant Biol. 6:13-19

31. Hayama R, Agashe B, Luley E, King R, Coupland G. 2007. A circadian rhythm set by dusk determines the expression of $F T$ homologs and the short-day photoperiodic flowering response in Pharbitis. Plant Cell 19:2988-3000

32. Hayama R, Coupland G. 2004. The molecular basis of diversity in the photoperiodic flowering responses of Arabidopsis and rice. Plant Physiol. 135:677-84

33. Hsu CY, Liu Y, Luthe DS, Yuceer C. 2006. Poplar FT2 shortens the juvenile phase and promotes seasonal flowering. Plant Cell 18:1846-61

34. Imaizumi T, Kay SA. 2006. Photoperiodic control of flowering: not only by coincidence. Trends Plant Sci. 11:550-58

35. Imaizumi T, Schultz TF, Harmon FG, Ho LA, Kay SA. 2005. FKF1 F-box protein mediates cyclic degradation of a repressor of CONSTANS in Arabidopsis. Science 309:29397

36. Imaizumi T, Tran HG, Swartz TE, Briggs WR, Kay SA. 2003. FKF1 is essential for photoperiodic-specific light signalling in Arabidopsis. Nature 426:302-6

37. Imlau A, Truernit E, Sauer N. 1999. Cell-to-cell and long-distance trafficking of the green fluorescent protein in the phloem and symplastic unloading of the protein into sink tissues. Plant Cell 11:309-22

38. Jaeger KE, Graf A, Wigge PA. 2006. The control of flowering in time and space. F. Exp. Bot. 57:3415-18

39. Jaeger KE, Wigge PA. 2007. FT protein acts as a long-range signal in Arabidopsis. Curr. Biol. 17:1050-54 
40. Kardailsky I, Shukla VK, Ahn JH, Dagenais N, Christensen SK, et al. 1999. Activation tagging of the floral inducer FT. Science 286:1962-65

41. Kim SJ, Moon J, Lee I, Maeng J, Kim SR. 2003. Molecular cloning and expression analysis of a CONSTANS homologue, PnCOL1, from Pharbitis nil. F. Exp. Bot. 54:1879-87

42. King RW, Evans LT. 2003. Gibberellins and flowering of grasses and cereals: prizing open the lid of the "florigen" black box. Annu. Rev. Plant Biol. 54:307-28

43. King RW, Zeevaart JA. 1973. Floral stimulus movement in Perilla and flower inhibition caused by noninduced leaves. Plant Physiol. 51:727-38

44. Kobayashi Y, Kaya H, Goto K, Iwabuchi M, Araki T. 1999. A pair of related genes with antagonistic roles in mediating flowering signals. Science 286:1960-62

45. Kojima S, Takahashi Y, Kobayashi Y, Monna L, Sasaki T, et al. 2002. Hd3a, a rice ortholog of the Arabidopsis FT gene, promotes transition to flowering downstream of Hd1 under short-day conditions. Plant Cell Physiol. 43:1096-105

46. Koornneef M, Alonso-Blanco C, Peeters AJM, Soppe W. 1998. Genetic control of flowering time in Arabidopsis. Annu. Rev. Plant Physiol. Plant Mol. Biol. 49:345-70

47. Koornneef M, Hanhart CJ, van der Veen JH. 1991. A genetic and physiological analysis of late flowering mutants in Arabidopsis thaliana. Mol. Gen. Genet. 229:57-66

48. Lang A. 1952. Physiology of flowering. Annu. Rev. Plant Physiol. 3:265-306

49. Laubinger S, Marchal V, Le Gourrierec J, Wenkel S, Adrian J, et al. 2006. Arabidopsis SPA proteins regulate photoperiodic flowering and interact with the floral inducer CONSTANS to regulate its stability. Development 133:3213-22

50. Lee H, Suh SS, Park E, Cho E, Ahn JH, et al. 2000. The AGAMOUS-LIKE 20 MADS domain protein integrates floral inductive pathways in Arabidopsis. Genes Dev. 14:236676

51. Lifschitz E, Eshed Y. 2006. Universal florigenic signals triggered by FT homologues regulate growth and flowering cycles in perennial day-neutral tomato. F. Exp. Bot. 57:3405-14

52. Lifschitz E, Eviatar T, Rozman A, Shalit A, Goldshmidt A, et al. 2006. The tomato FT ortholog triggers systemic signals that regulate growth and flowering and substitute for diverse environmental stimuli. Proc. Natl. Acad. Sci. USA 103:6398-403

53. Lin MK, Belanger H, Lee YJ, Varkonyi-Gasic E, Taoka K, et al. 2007. FLOWERING LOCUS T protein may act as the long-distance florigenic signal in the cucurbits. Plant Cell 19:1488-506

54. Liu C, Zhou J, Bracha-Drori K, Yalovsky S, Ito T, Yu H. 2007. Specification of Arabidopsis floral meristem identity by repression of flowering time genes. Development 134:1901-10

55. Liu J, Yu J, McIntosh L, Kende H, ZeevaartJA. 2001. Isolation of a CONSTANS ortholog from Pharbitis nil and its role in flowering. Plant Physiol. 125:1821-30

56. Lough TJ, Lucas WJ. 2006. Integrative plant biology: role of phloem long-distance macromolecular trafficking. Annu. Rev. Plant Biol. 57:203-32

57. Maity SN, de Crombrugghe B. 1998. Role of the CCAAT-binding protein CBF/NF-Y in transcription. Trends Biochem. Sci. 23:174-78

58. Martin J, Storgaard M, Andersen CH, Nielsen KK. 2004. Photoperiodic regulation of flowering in perennial ryegrass involving a CONSTANS-like homolog. Plant Mol. Biol. 56:159-69

59. Mathieu J, Warthmann N, Kuttner F, Schmid M. 2007. Export of FT protein from phloem companion cells is sufficient for floral induction in Arabidopsis. Curr. Biol. 17:105560

60. Michaels SD, Himelblau E, Kim SY, Schomburg FM, Amasino RM. 2005. Integration of flowering signals in winter-annual Arabidopsis. Plant Physiol. 137:149-56 
61. Mimida N, Goto K, Kobayashi Y, Araki T, Ahn JH, et al. 2001. Functional divergence of the TFL1-like gene family in Arabidopsis revealed by characterization of a novel homologue. Genes Cells 6:327-36

62. Mizoguchi T, Wright L, Fujiwara S, Cremer F, Lee K, et al. 2005. Distinct roles of GIGANTEA in promoting flowering and regulating circadian rhythms in Arabidopsis. Plant Cell 17:2255-70

63. Mockler T, Yang H, Yu X, Parikh D, Cheng YC, et al. 2003. Regulation of photoperiodic flowering by Arabidopsis photoreceptors. Proc. Natl. Acad. Sci. USA 100:2140-45

64. Molinero-Rosales N, Latorre A, Jamilena M, Lozano R. 2004. SINGLE FLOWER TRUSS regulates the transition and maintenance of flowering in tomato. Planta 218:42734

65. Onouchi H, Igeno MI, Perilleux C, Graves K, Coupland G. 2000. Mutagenesis of plants overexpressing CONSTANS demonstrates novel interactions among Arabidopsis flowering-time genes. Plant Cell 12:885-900

66. Oparka KJ, Cruz SS. 2000. The great escape: phloem transport and unloading of macromolecules. Annu. Rev. Plant Physiol. Plant Mol. Biol. 51:323-47

67. Parcy F. 2005. Flowering: a time for integration. Int. F. Dev. Biol. 49:585-93

68. Pittendrigh CS, Minis DH. 1964. The entrainment of circadian oscillations by light and their role as photoperiodic clocks. Am. Nat. 98:261-322

69. Pnueli L, Carmel-Goren L, Hareven D, Gutfinger T, Alvarez J, et al. 1998. The SELFPRUNING gene of tomato regulates vegetative to reproductive switching of sympodial meristems and is the ortholog of CEN and TFL1. Development 125:1979-89

70. Putterill J, Robson F, Lee K, Simon R, Coupland G. 1995. The CONSTANS gene of Arabidopsis promotes flowering and encodes a protein showing similarities to zinc finger transcription factors. Cell 80:847-57

71. Ratcliffe OJ, Amaya I, Vincent CA, Rothstein S, Carpenter R, et al. 1998. A common mechanism controls the life cycle and architecture of plants. Development 125:1609-15

72. Reeves PH, Coupland G. 2001. Analysis of flowering time control in Arabidopsis by comparison of double and triple mutants. Plant Physiol. 126:1085-91

73. Robert LS, Robson F, Sharpe A, Lydiate D, Coupland G. 1998. Conserved structure and function of the Arabidopsis flowering time gene CONSTANS in Brassica napus. Plant Mol. Biol. 37:763-72

74. Robson F, Costa MM, Hepworth SR, Vizir I, Pineiro M, et al. 2001. Functional importance of conserved domains in the flowering-time gene CONSTANS demonstrated by analysis of mutant alleles and transgenic plants. Plant 7. 28:619-31

75. Roden LC, Song HR, Jackson S, Morris K, Carre IA. 2002. Floral responses to photoperiod are correlated with the timing of rhythmic expression relative to dawn and dusk in Arabidopsis. Proc. Natl. Acad. Sci. USA 99:13313-18

76. Ruiz-García L, Madueño F, Wilkinson M, Haughn G, Salinas J, Martínez-Zapater JM. 1997. Different roles of flowering-time genes in the activation of floral initiation genes in Arabidopsis. Plant Cell 9:1921-34

77. Samach A, Onouchi H, Gold SE, Ditta GS, Schwarz-Sommer Z, et al. 2000. Distinct roles of CONSTANS target genes in reproductive development of Arabidopsis. Science 288:1613-16

78. Sawa M, Nusinow DA, Kay SA, Imaizumi T. 2007. FKF1 and GIGANTEA complex formation is required for day-length measurement in Arabidopsis. Science 318:261-65

79. Searle I, Coupland G. 2004. Induction of flowering by seasonal changes in photoperiod. EMBO 7. 23:1217-22 
80. Searle I, He Y, Turck F, Vincent C, Fornara F, et al. 2006. The transcription factor FLC confers a flowering response to vernalization by repressing meristem competence and systemic signaling in Arabidopsis. Genes Dev. 20:898-912

81. Shin BS, Lee JH, Lee JH, Jeong HJ, Yun CH, Kim JK. 2004. Circadian regulation of rice (Oryza sativa L.) CONSTANS-like gene transcripts. Mol. Cells 17:10-16

82. Simon R, Igeno MI, Coupland G. 1996. Activation of floral meristem identity genes in Arabidopsis. Nature 384:59-62

83. Simpson GG, Gendall AR, Dean C. 1999. When to switch to flowering. Annu. Rev. Cell Dev. Biol. 15:519-50

84. Soppe WJ, Jacobsen SE, Alonso-Blanco C, Jackson JP, Kakutani T, et al. 2000. The late flowering phenotype of fwa mutants is caused by gain-of-function epigenetic alleles of a homeodomain gene. Mol. Cell 6:791-802

85. Suarez-Lopez P, Wheatley K, Robson F, Onouchi H, Valverde F, Coupland G. 2001. CONSTANS mediates between the circadian clock and the control of flowering in Arabidopsis. Nature 410:1116-20

86. Takada S, Goto K. 2003. Terminal flower2, an Arabidopsis homolog of heterochromatin protein 1, counteracts the activation of flowering locus $T$ by constans in the vascular tissues of leaves to regulate flowering time. Plant Cell 15:2856-65

87. Tamaki S, Matsuo S, Wong HL, Yokoi S, Shimamoto K. 2007. Hd3a protein is a mobile flowering signal in rice. Science 316:1033-36

88. Teper-Bamnolker P, Samach A. 2005. The flowering integrator FT regulates SEPALLATA3 and FRUITFULL accumulation in Arabidopsis leaves. Plant Cell 17:266175

89. Torok M, Etkin LD. 2001. Two B or not two B? Overview of the rapidly expanding B-box family of proteins. Differentiation 67:63-71

90. Turck F, Roudier F, Farrona S, Martin-Magniette ML, Guillaume E, et al. 2007. Arabidopsis TFL2/LHP1 specifically associates with genes marked by trimethylation of histone H3 lysine 27. PLoS Genet. 3:e86

91. Turner A, Beales J, Faure S, Dunford RP, Laurie DA. 2005. The pseudoresponse regulator Ppd-H1 provides adaptation to photoperiod in barley. Science 310:1031-34

92. Valverde F, Mouradov A, Soppe W, Ravenscroft D, Samach A, Coupland G. 2004. Photoreceptor regulation of CONSTANS protein in photoperiodic flowering. Science 303:1003-6

93. Weigel D. 1995. The genetics of flower development: from floral induction to ovule morphogenesis. Annu. Rev. Genet. 29:19-39

94. Wenkel S, Turck F, Singer K, Gissot L, Le Gourrierec J, et al. 2006. CONSTANS and the CCAAT box binding complex share a functionally important domain and interact to regulate flowering of Arabidopsis. Plant Cell 18:2971-84

95. Wigge PA, Kim MC, Jaeger KE, Busch W, Schmid M, et al. 2005. Integration of spatial and temporal information during floral induction in Arabidopsis. Science 309:1056-59

96. Wilson RN, Heckman JW, Somerville CR. 1992. Gibberellin is required for flowering in Arabidopsis thaliana under short days. Plant Physiol. 100:403-8

97. Yamaguchi A, Kobayashi Y, Goto K, Abe M, Araki T. 2005. TWIN SISTER OF FT (TSF) acts as a floral pathway integrator redundantly with FT. Plant Cell Physiol. 46:117589

98. Yano M, Katayose Y, Ashikari M, Yamanouchi U, Monna L, et al. 2000. Hd1, a major photoperiod sensitivity quantitative trait locus in rice, is closely related to the Arabidopsis flowering time gene CONSTANS. Plant Cell 12:2473-84 
99. Yanovsky MJ, Kay SA. 2002. Molecular basis of seasonal time measurement in Arabidopsis. Nature 419:308-12

100. Yoo SK, Chung KS, Kim J, Lee JH, Hong SM, et al. 2005. CONSTANS activates SUPPRESSOR OF OVEREXPRESSION OF CONSTANS 1 through FLOWERING LOCUS T to promote flowering in Arabidopsis. Plant Physiol. 139:770-78

101. Yoo SY, Kardailsky I, Lee JS, Weigel D, Ahn JH. 2004. Acceleration of flowering by overexpression of MFT (MOTHER OF FT AND TFL1). Mol. Cells 17:95-101

102. Zeevaart JAD. 1976. Physiology of flower formation. Annu. Rev. Plant Physiol. 27:321-48 
Annual Review of Plant Biology

Our Work with Cyanogenic Plants

Eric E. Conn ........................................................... 1

New Insights into Nitric Oxide Signaling in Plants

Angélique Besson-Bard, Alain Pugin, and David Wendehenne.

Plant Immunity to Insect Herbivores

Gregg A. Howe and Georg Fander

Patterning and Polarity in Seed Plant Shoots

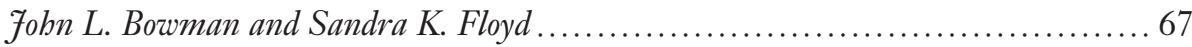

Chlorophyll Fluorescence: A Probe of Photosynthesis In Vivo

Neil R. Baker

Seed Storage Oil Mobilization

Ian A. Graham

The Role of Glutathione in Photosynthetic Organisms:

Emerging Functions for Glutaredoxins and Glutathionylation

Nicolas Roubier, Stéphane D. Lemaire, and Fean-Pierre facquot

Algal Sensory Photoreceptors

Peter Hegemann

Plant Proteases: From Phenotypes to Molecular Mechanisms Renier A.L. van der Hoorn

Gibberellin Metabolism and its Regulation

Shinjiro Yamaguchi

Molecular Basis of Plant Architecture

Yonghong Wang and fiayang $\mathrm{Li}$

Decoding of Light Signals by Plant Phytochromes and Their Interacting Proteins

Gabyong Bae and Giltsu Choi

Flooding Stress: Acclimations and Genetic Diversity

7. Bailey-Serres and L.A.C.7. Voesenek 
Roots, Nitrogen Transformations, and Ecosystem Services

Louise E. Fackson, Martin Burger, and Timothy R. Cavagnaro

A Genetic Regulatory Network in the Development of Trichomes and Root Hairs

Tetsuya Ishida, Tetsuya Kurata, Kiyotaka Okada, and Takuji Wada

Molecular Aspects of Seed Dormancy

Ruth Finkelstein, Wendy Reeves, Tobru Ariizumi, and Camille Steber

Trehalose Metabolism and Signaling

Matthew 7. Paul, Lucia F. Primavesi, Deveraj Fhurreea, and Yuhua Zhang

Auxin: The Looping Star in Plant Development

René Benjamins and Ben Scheres

Regulation of Cullin RING Ligases

Sara K. Hotton and Fudy Callis

Plastid Evolution

Sven B. Gould, Ross F. Waller, and Geoffrey I. McFadden

Coordinating Nodule Morphogenesis with Rhizobial Infection in Legumes

Giles E.D. Oldroyd and 7. Allan Downie

Structural and Signaling Networks for the Polar Cell Growth

Machinery in Pollen Tubes

Alice Y. Cheung and Hen-ming $W u$

Regulation and Identity of Florigen: FLOWERING LOCUS T Moves

Center Stage

Franziska Turck, Fabio Fornara, and George Coupland

Plant Aquaporins: Membrane Channels with Multiple Integrated Functions

Christophe Maurel, Lionel Verdoucq, Doan-Trung Luu, and Véronique Santoni ....595

Metabolic Flux Analysis in Plants: From Intelligent Design

to Rational Engineering

Igor G.L. Libourel and Yair Shachar-Hill

Mechanisms of Salinity Tolerance

Rana Munns and Mark Tester. ...

Sealing Plant Surfaces: Cuticular Wax Formation by Epidermal Cells

Lacey Samuels, Ljerka Kunst, and Reinhard Fetter

Ionomics and the Study of the Plant Ionome

David E. Salt, Ivan Baxter, and Brett Lahner 
Alkaloid Biosynthesis: Metabolism and Trafficking Förg Ziegler and Peter 7. Facchini...

Genetically Engineered Plants and Foods: A Scientist's Analysis of the Issues (Part I)

Peggy G. Lemaux

\section{Indexes}

Cumulative Index of Contributing Authors, Volumes 49-59 813

Cumulative Index of Chapter Titles, Volumes 49-59 818

\section{Errata}

An online log of corrections to Annual Review of Plant Biology articles may be found at http://plant.annualreviews.org/ 